Wiraraja Medika : Jurnal Kesehatan
https://www.ejournalwiraraja.com/index.php/FIK
2088-415x (Print)|2685-9998 (online)

\title{
Gaya Hidup Berhubungan dengan Hipertensi
}

\author{
Emdat Suprayitno $^{1}$, Sri Sumarni ${ }^{2}$, Isqi lailatul islami ${ }^{3}$ \\ ${ }^{1}$ Program Studi Profesi Ners Fakultas Ilmu Kesehatan Universitas Wiraraja \\ ${ }^{2,3}$ Program Studi Keperawatan Fakultas Ilmu Kesehatan Universitas Wiraraja \\ emdat@wiraraja.ac.id*
}

*Corresponding author

\begin{tabular}{l}
\hline INFORMASI ARTIKEL \\
\hline Sejarah artikel: \\
Received: $04-10-2020$ \\
Revised: $11-11-2020$ \\
Accepted: 30-11-2020 \\
\hline Kata kunci: \\
Hipertensi, gaya hidup, \\
kejadian hipertensi
\end{tabular}

\begin{abstract}
ABSTRAKM
Hipertensi menjadi masalah utama sebagai faktor risiko kematian pada penyakit kardiovaskular yang disebabkan oleh faktor genetik dan gaya hidup. Tujuan penelitian ini adalah menganalisis hubungan hipertensi dengan gaya hidup di Desa Poja Kecamatan Gapura. Penelitian ini menggunakan desain analitik cross sectional. Populasi dalam penelitian ini yaitu sebanyak 73 orang. Teknik pengambilan sampel dengan simple random sampling dan analisa data menggunakan uji Chi Square, teknik pengumpulan data menggunakan forms kuesioner online (google forms). Hasil uji chi square di dapatkan $\mathrm{P}$ value $=0,001<a(0,05)$ yang berarti terdapat hubungan hipertensi dengan gaya hidup di Desa Poja Kecamatan Gapura. Oleh karena itu penting selkali menerapkan gaya hidup yang baik dan sehat untuk mencegah terjadinya hipertensi.

\section{ABSTRACT}

Hypertension is a major problem as a risk factor for death in cardiovascular disease caused by genetic and lifestyle factors. The purpose of this study was to analyze the relationship between hypertension and lifestyle in Poja Village, Gapura District. This study used a cross sectional analytic design. The population in this study were 73 people. The sampling technique was simple random sampling and data analysis used the Chi Square test, the data collection technique used online questionnaire forms (google forms). Chi square test results obtained $P$ value $=0.001<a(0.05)$, which means that there is a relationship between hypertension and lifestyle in Poja Village, Gapura District. Therefore it is important to always adopt a good and healthy lifestyle to prevent hypertension.
\end{abstract}

Key word:

Hypertension, lifestyle, the incidence of hypertension

\section{PENDAHULUAN}

Hipertensi adalah penyakit tidak menular dan menjadi faktor utama permasalahan kesehatan di dunia karena prevalensinya yang masih tinggi (Eriana, 2017). Hipertensi menjadi tantangan besar di Indonesia karena sering ditemukan pada pelayanan kesehatan tingkat primer atau di puskesmas. Hipertensi dapat membunuh penderitanya secara diam-diam yang merupakan the silent killer disebabkan karena sering tanpa bergejala dan penderitanya jarang menyadarinya (Suprayitno, 2019). Menurut Ariff Dkk (2011) Hipertensi merupakan permasalahan dalam kesehatan di seluruh dunia karena tingkat kejadiannya yang sangat tinggi serta tanda gejalanya dapat membahayakan, hipertensi di tahun 2025 diperkirakan akan meningkat sekitar $60 \%$ menjadi total 1,56 miliar (1,54-1,58 miliar).

Menurut Suoth (2014) Gaya hidup menjadi faktor penting dalam mempengaruhi pola hidup. Pola kebiasaan hidup kurang sehat dapat mengakibatkan terjangkitnya penyakit hipertensi, dimana tingkat kejadiannya selalu bertambah mengikuti adanya berubahnya gaya hidup, misalnya dalam cara makan, aktifitas fisik, dan Kebiasaan merokok (Suoth dkk, 2014). Berdasarkan studi awal pendahuluan yang dilakukan pada tanggal 16 November 2019 di Desa Poja Kecamatan Gapura bahwa dari hasil wawancara didapatkan data dari 13 orang penderita hipertensi, 3 orang mengatakan bahwa mereka lebih suka 
kosumsi makanan asin seperti telor asin, petis, terasi, ikan asin, gorengan, sedangkan 4 orang lainnya mengatakan suka mengkonsumsi makanan yang berkadar lemak tinggi seperti kaldu, kripik paru, jeroan, gorengan, 2 orang mengungkapkan bahwa kurang melakukan aktivitas fisik seperti olahraga setiap hari, sedangkan 2 orang lainnya mengungkapkan bahwa sering melakukan aktivitas sehari-hari seperti pekerjaan rumah, dan 2 orang lainnya termasuk perokok aktif. Menurut data WHO tahun 2014 disebutkan sekitar 600 juta penderita hipertensi di seluruh dunia, dimana kejadian tertinggi terdapat di Afrika sebesar 30 \% (Yuwono, 2017).

Angka kejadian penyakit hipertensi menurut hasil pemeriksaan kepada masyarakat berumur lebih dari 18 tahun di Indonesia tahun 2013-2018 relatif meningkat pada tahun 2013 angka prevalensinya yaitu $25.8 \%$ sedangkan 2018 angka prevalensinya yaitu $34.1 \%$. Jumlah kejadian penyakit hipertensi menurut pemeriksaan kepada usia lebih dari 18 tahun di Provinsi Jawa Timur tahun 20132018 relatif meningkat pada tahun 2013 angka prevalensinya yaitu $26,2 \%$ sedangkan 2018 angka prevalensinya yaitu 36,32 \% (Riskesdas, 2018). Menurut validasi data bulan maret tahun 2019 penyakit hipertensi menurut Kabupaten/Kota Sumenep jumlah kasus tahun 2018 sebesar 31.320 kasus (Dinkes, 2019). Data penyakit hipertensi di puskesmas gapura kecamatan gapura bulan januari-desember tahun 2018 karakteristik pada laki-laki mencapai 387 kasus sedangkan perempuan mencapai 499 kasus, sedangkan pada bulan januaridesember tahun 2019 karakteristik pada laki-laki mencapai 286 kasus sedangkan perempuan 356 kasus.

faktor resiko terjadinya hipertensi salah atunya adalah gaya hidup seseorang seperti makan tinggi lemak dan konsumsi makanan yang mengandung tinggi garam, berat badan berlebih dan makan dalam jumlah yang tidak terkontrol, Gaya hidup kurang sehat isalnya konsumsi minuman beralkohol, perilaku merokok, kejadian stress dan jarang melakukan aktifitas fisik, berat badan berlebih, dampak dari gaya hidup kurang sehat dapat mengakibatkan kejadian hipertensi meningkat (Hanafi, 2016). Penyebab terjadinya hipertensi juga disebabkan oleh beberapa faktor risiko antara lain yaitu umur, jenis kelamin, riwayat keluarga, dan genetik (Manuntung,
2018). hasil penelitian sebelumnya yang dilakukan oleh Arifin Dkk (2016) menyebutkan jika ada hubungan bermakna diantara faktor genetik, stress dan kebiasaaan olahraga dengan terjadinya hipertensi. Tujuan penelitian ini untuk mengetahui hubungan gaya hidup dengan hipertensi di Desa Poja Kecanaran Gapura.

\section{METODE PENELITIAN}

Metode Penelitian yang digunakan adalah desain analitik korelasional dengan rancang bangun cross sectional. Sampel dalam penelitian ini yaitu 73 orang. Teknik pengambilan sampel dengan simple random sampling. Penelitian ini memiliki variabel independen gaya hidup (Aktivitas fisik, pola makan, kebiasaan merokok) dan variabel dependen yaitu kejadian penyakit hipertensi. Penelitian ini menjelaskan tentang ada dan tidaknya hubungan antara dua variabel. Pengambian data dilakukan secara online menggunakan google form yang disebarkan ke 73 responden.

\section{HASIL PENELITIAN}

Tabel 1 Data Umum Responden

\begin{tabular}{|c|c|c|}
\hline Karakteristik & $\mathbf{F}$ & (\%) \\
\hline \multicolumn{3}{|l|}{ Usia } \\
\hline $31-40$ & 2 & 2,7 \\
\hline$>40$ & 71 & 97,3 \\
\hline \multicolumn{3}{|l|}{ Jenis kelamin } \\
\hline Laki-Laki & 29 & 39,7 \\
\hline Perempuan & 44 & 60,3 \\
\hline \multicolumn{3}{|l|}{ Pendidikan } \\
\hline Tidak Sekolah & 2 & 2,7 \\
\hline $\mathrm{SD} / \mathrm{MI}$ & 39 & 53,4 \\
\hline SMP/MTS & 22 & 30,1 \\
\hline SMA/MA & 10 & 13,7 \\
\hline \multicolumn{3}{|l|}{ Pekerjaan } \\
\hline Tidak Bekerja & 9 & 12,3 \\
\hline Pedagang & 9 & 12,3 \\
\hline Petani & 44 & 60,3 \\
\hline PNS/Pensiun PNS & 8 & 11 \\
\hline $\begin{array}{c}\text { Swasta/ } \\
\text { Wiraswasta }\end{array}$ & 3 & 4,1 \\
\hline Jumlah & 73 & $100 \%$ \\
\hline $\begin{array}{l}\text { Berdasarkan } \\
\text { menunjukkan bahn } \\
\text { responden berusia } \\
\text { sebanyak } 71 \text { orang } 9 \\
\text { responden berjenis } \\
\text { yaitu sebanyak } 44 \text { or }\end{array}$ & $\begin{array}{r}\text { ta } \\
\mathrm{h} \\
40 \\
3 \%) \\
3 \% \\
\text { lami }\end{array}$ & $\begin{array}{r}\text { diatas } \\
\text { seluruh } \\
\text { n, yaitu } \\
\text { rian besar } \\
\text { rempuan, } \\
\text { sebagian }\end{array}$ \\
\hline
\end{tabular}


besar responden dengan tingkat pendidikan adalah SD/MI, yaitu sebanyak 39 orang (53,4 \%). sebagian besar responden bekerja sebagai Petani, yaitu sebanyak 44 orang 60,3\%).

Tabel 2 Distribusi Gaya Hidup di Desa Poja Kecamatan Gapura.

\begin{tabular}{ccc}
\hline Gaya Hidup & Frekuensi & Presentase \\
\hline Baik & 22 & 30 \\
Cukup & 51 & 70 \\
\hline jumlah & 73 & 100 \\
\hline
\end{tabular}

Berdasarkan tabel diatas menunjukkan bahwa sebagian besar gaya hidup termasuk kategori cukup, yaitu sebanyak 51 orang (70\%).

Tabel 3 Distribusi responden berdasarkan hipertensi di Desa Poja Kecamatan Gapura.

\begin{tabular}{ccc}
\hline Hipertensi & Frekuensi & Presentase \\
\hline Ringan & 8 & $11 \%$ \\
Berat & 65 & $89 \%$ \\
\hline Jumlah & 73 & 100 \\
\hline \multicolumn{4}{c}{ Berdasarkan } & tabel & $\begin{array}{r}\text { diatas } \\
\text { seluruh }\end{array}$ \\
menunjukkan bahwa hampir & berajat 2, \\
responden mengalami hipertensi Derajat 2 \\
yaitu sebanyak 65 orang (89,0\%).
\end{tabular}

Tabel 4 Hubungan Hipertensi dengan Gaya Hidup di Desa Poja Kecamatan Gapura

\begin{tabular}{|c|c|c|c|c|c|c|}
\hline \multirow{3}{*}{ Hipertensi } & \multicolumn{4}{|c|}{ Gaya hidup } & \multirow{2}{*}{\multicolumn{2}{|c|}{ Jumlah }} \\
\hline & \multicolumn{2}{|c|}{ Cukup } & \multicolumn{2}{|c|}{ Kurang } & & \\
\hline & $\mathrm{F}$ & $\%$ & $\mathrm{~F}$ & $\%$ & & \\
\hline Ringan & 2 & 2,7 & 6 & 8,2 & $\begin{array}{l}8 \\
6\end{array}$ & 11 \\
\hline Berat & 1 & 1,4 & 64 & 88 & 5 & 89 \\
\hline Jumlah & 3 & 4,1 & 70 & 96 & $\begin{array}{l}7 \\
3 \\
\end{array}$ & $\begin{array}{c}10 \\
0\end{array}$ \\
\hline \multicolumn{7}{|c|}{ Pvalue: 0,001} \\
\hline
\end{tabular}

Hasil uji statistik menggunakan uji chi square diperoleh $\rho$ value $=0,001$ dengan nilai $a=0,05$, jadi $\rho(0,001)<a(0,05)$ berarti terdapat hubungan hipertensi dengan gaya hidup di Desa Poja Kecamatan Gapura.

\section{PEMBAHASAN}

Hubungan Hipertensi dengan gaya hidup Berdasarkan Uji korelasi Pvalue = $0,001<a 0,05$ yang berarti ada hubungan hipertensi dengan gaya hidup di Desa Poja Kecamatan Gapura. Faktor resiko gaya hidup pada penyakit hipertensi tidak memandang usia seseorang, termasuk usia dewasa muda (21-40 tahun) sudah ada yang mengalami penyakit hipertensi. Meningkatnya kejadian seperti: merokok, kurang olahraga, konsumsi makanan berlemak dan stres (Fadhli, 2018). Teori ini sesuai dengan pernyataan bahwa Gaya hidup yang mengutamakan kesuksesan, bekerja dengan keras, pada saat tertekan, dan mengalami stres yang lama, kurang aktifitas, merokok, konsumsi alkohol dimana semuanya adalah penyebab hipertensi (Suprayitno et all, 2020)

Gaya hidup yang berubah dan kurang menerapkan kehidupan yang sehat menyebabkan banyak masalah kesehatan, diakibatkan karena gaya hidup yang tidak sehat meliputi pola makan yang salah, perokok aktif, mengalami stress, dari kebiasaan tersebut dapat menjadi faktor dominan yang menyebabkan seseorag mengalami masalah kesehatan salah satunya dalam sistem kardiovaskuler yaitu hipertensi (Damayanti, 2020). Melalui upaya kontrol hipertensi dapat dilihat tingkat kepatuhan pasien terhadap perbaikan pola hidup, kepatuhan untuk melakukan olahraga, kepatuhan melaksanakan diet rendah garam, kepatuhan mengkonsumsi obat anti hipertensi, kecocokan obat anti hipertensi yang diberikan, dan kemajuan terapi terhadap penurunan tekanan darah. Jadi tujuan upaya kontrol bagi pengidap hipertensi adalah mengendalikan hipertensi dan mencegah komplikasi akibat hipertensi (Gardani ,2012).

Berdasarkan teori dan hasil penelitian tersebut, penderita hipertensi dengan Riwayat merokok, konsumsi minuman beralkohol dan berkafein, serta mengkonsumsi makanan yang berlemak serta kurangnya olahraga, perlu mendapat himbauan dari petugas kesehatan dan keluarga yang mendukung agar bisa merubah gaya hidup yang kurang baik ke arah gaya hidup yang lebih sehat sehingga dapat mencegah bahaya resiko penyakit hipertensi (Suprayitno, \& Wahid, 2019). Sejalan dengan penelitian Ariff F Dkk 
(2011), bahwa ada hubungan yang signifikan antara hipertensi dan gaya hidup serta Faktor gaya hidup, menunjukkan risiko hipertensi yang secara signifikan lebih rendah dibandingkan dengan mereka yang memiliki skor rendah (Rasio Odds 0,546). Hal ini sesuai dengan pendapat Suoth Dkk (2014), gaya hidup sehat meliputi pola makan sehat, aktivitas fisik yang cukup, menghindari rokok dan menkonsumsi alkohol, secara teratur melakukan olahraga. sejalan dengan penelitian Aminuddin Dkk (2019), bahwa mayoritas responden mengkonsumsi garam dan memiliki kebiasaaan aktifitas fisik kurang baik.

Faktor peningkatan tekanan darah sangat perlu diperhatikan karena gaya hidup yang tidak sehat menjadi faktor dominan yang urang diperhatikan masyarakat. masyarakat harus lebih memperhatikan gaya hidupnya agar dapat memperkecil faktor komplikasi dari hipertensi (Suprayitno,E \& Huzaimah,N., 2020). Hasil penelitian mayoritas menunjukkan bahwa masalah yang kerap terjadi yaitu kurang menjaga pola makan yang sehat, kurangnya aktivitas fisik, sering mengkonsumsi minuman yang berkafein, kurangnya berolahraga, sehingga responden tidak dapat mengatur diri dalam gaya hidup yang sehat. Dari penjabaran diatas menunjukkan bahwa adanya hubungan yang signifikan antara hubungan hipertensi dengan gaya hidup.

\section{KESIMPULAN}

Sebagian besar gaya hidup responden termasuk kategori cukup dan derajat hipertesi Sebagian besar responden adalah hipertensi derajat II. Terdapat hubungan hipertensi dengan gaya hidup di desa poja kecamatan gapura. Oleh karena itu penderita hipertensi disarankan agar melakukan gaya hidup sehat untuk mencegah komplikasi penyakit hipertensi.

\section{DAFTAR PUSTAKA}

Ariff, F., Suthahar, A., \& Ramli, M. (2011). Coping styles and lifestyle factors among hypertensive and nonhypertensive subjects. 52(1), 29-34.

Arifin, M. H. B. M., \& Weta, I. W. (2016). Faktor-Faktor Yang Berhubungan Dengan Kejadian Hipertensi Pada Kelompok Lanjut Usia Di Wilayah Kerja Upt Puskesmas Petang I Kabupaten Badung Tahun 2016. E-Jurnal Medika
Udayana, 5(7).

Damayanti, C. N., Hannan, M., \& Fatoni, A. F. (2019). Efektifitas Pendidikan Kesehatan Terhadap Tekanan Darah Pada Lansia. WIRARAJA MEDIKA, 9(2), 46-51.

Dinkes. (2018). Hasil Utama Riset Kesehatan Dasar Jawa Timur 2018. Jakarta: Badan Penelitian Dan Pengembangan Kesehatan, Kementrian Kesehatan Republik Indonesia, 1-82.

Eriana, I. (2017). Hubungan Gaya Hidup Dengan Kejadian Hipertensi Pada Pegawai Negeri Sipil Uin Alauddin Makassar Tahun 2017. Universitas Islam Negeri Alauddin Makassar.

Fadhli, Muh Wendi .(2018). Hubungan Antara Gaya Hidup Dengan Kejadian Hipertensi Pada Usia Dewasa Muda Di Desa Lamakan Kecamatan Karamat Kabupaten Buol. Jurnal Kesmas, 7(6).

Gardani, Yudi. (2012). Hidup Nyaman Dengan Hipertensi. Jakarta : Agromedika Pustaka.

Hanafi, A. (2016). Gambaran Gaya Hidup Penderita Hipertensi Di Kecamatan Sumowono Kabupaten Semarang. Skripsi.

Https://Doi.Org/10.1001/Archgenpsyc hiatry.2009.194

Manuntung, Alfeus. (2018). Terapi Perilaku Kognitif Pada Pasien Hipertensi. Malang : Wineka Media. 12 November 2019.

Suoth, M., Bidjuni, H., \& Malara, R. (2014). Hubungan Gaya Hidup Dengan Kejadian Hipertensi Di Puskesmas Kolongan Kecamatan Kalawat Kabupaten Minahasa Utara. Jurnal Keperawatan, 2(1).

Suprayitno, E., Damayanti, C. N., \& Hannan, M. (2019). Gambaran Status Tekanan Darah Penderita Hipertensi Di Desa Karanganyar Kecamatan Kalianget Kabupaten Sumenep. Journal Of Health Science (Jurnal Ilmu Kesehatan), 4(2), 20-24.

Suprayitno, Emdat, Purnomo, J. D. T., Sutikno, S., \& Indriyani, R. (2020). Health education in principle of community affected teenagaer's smooking attitude and habitual in the coastal area of madura island indonesia. International Journal of Psychosocial Rehabilitation, 24(10), 1492-1502. https://doi.org/10.37200 /IJPR/V24I10/PR300173

Suprayitno, E., \& Huzaimah, N. (2020). 
Pendampingan lansia dalam pencegahan komplikasi hipertensi. Selaparang Jurnal Pengabdian Masyarakat Berkemajuan, 4(1), 518521.

Suprayitno, E, \& Wahid, A. (2019). Pendampingan Tentang Penyakit Hipertensi Dan Perawatan Keluarga Dengan Hipertensi. Seminar Nasional
Hasil Pengabdian ..., 104-106. http://proceeding.uim.ac.id/index.ph $\mathrm{p} / \mathrm{senias} /$ article/view/299

Yuwono, G. A., Ridwan, M., \& Hanafi, M. (2018). Pengaruh Pendidikan Kesehatan Tentang Hipertensi Terhadap Tingkat Kecemasan Pada Penderita Hipertensi Di Kabupaten Magelang. Jurnal Keperawatan Soedirman, 12(1), 55-66. 